changed, on both oceasions registering $3 \pi$ per cent. division of two drops; nevertheless he gained markedly in weight and in health and strength. I am somewhat inclined to the belief that the destructive action of the quinin on the red bloodcorpuscles neutralized in a way the good effects obtained by the administration of arsenic. Ire then is an unmistakable case of malarial hemoglobinuria which was given quinin during the time of the passage of the blood, yet the blood in the urine, so far from increasing, steadily diminished. I have never seen an instance of hemoglobinuria in one of the regularly malarial intermittents, but have no doubt that if such oceur, the result would be more favorable under quinin even than the case I have just reported. I do not think that even if quinin does produce hemoglobinuria in malaria, which $\Upsilon$ do not believe, that factor alone should deter us from using a drug which is almost a specific to the disease which we do know is frequently accompanied by this complication.

In regard to hypodermic injections, I wish briefy to state my experience with 7 cases of malaria all treated in this manner: all young adult males with fairly good family history; all of tertian malaria, 6 double and 1 single, in all of which the diagnosis was made by microscopic examination. In 3 all manifestations of the disease were stopped by one injec. tion; in but 1 was no influence felt by one injection; in but 1 case was more than 6 grains given at a dose; the bisulphate was the preparation of the quinin used; all the injections but one were made deep in the gluteal region; very little pain was experienced, and that only at the time of the injection; but ten injections were used in all; no abscesses resulted from their use. In the cases in which an endeavor was made to change a quotidian or double tertian malaria into a single tertian by hypodermic injection of quinin, 1 was completely successful; 2 were partially suceessful; 3 were unsuccessful. Of these 3 cases 2 were completely cured by one injection, as shown by subsequent clinical history and blood examinaiton; the remaining case was not much affected. I might say in conclusion that the injections were given at the very beginning of the chill. Very truly yours,

MaRK A. BRown, M.D.

\section{Dr. Murphy's Letter on Optical Diagrams.} Richmond, Ind., July 31, 1899.

T'o the Editor:-In the Journal of July 29, there is a letter by Dr. Murphy of Kansas City as to "Misleading Statements and Illustrations in School Physiologies, Physics, and in TextBooks on Diseases of the Eye," but unfortunately in this case it is Dr. Murphy who is misleading. He states that the textbooks teach that parallel rays of light focus on the retina in the normal eye. This is just what they have taught, do teach, and always ought to teach.

The first three illustrations, which he states are incorrectly drawn, are just as correct as his Figures 5, 6 and 7 . Possibly some slight objection may be made to them all, in that they take for their basis the old ray theory, which is entirely superseded by the wave theory.

Scheiner's experiment any one can perform by taking a visiting card through which two pinholes have been pierced, the distance between which is less than the diameter of the pupil; it will be found that if this diaphragm is held close to the eye while a bright star is being observed, and the subject is ametropic, there will appear to be two stars. If the upper right pinhole is covered with a red glass, while the subject is hyperopic, the red star will appear below; whereas, if myopic, the red star will appear to the observer as if from above. In the emmetropic there will be a fusion of the red and white stars into one.

This merely proves that Figures 1, 2, and 3 are consistent, for waves or rays from a star, that enter the pupil, are parallel. If we can suppose a case in which the upper part of the star was flattened so that we could tell it from the lower part, then in Sheiner's experiment, no matter if the observer was myopic, emmetropic, or hyperopic, in every case the flattened part of the star would face the lower part of the retina, while to the observer it would appear erect with the flattened part at the top, as in Nature. DAvid W. Stevenson, M.D.

\section{Retention of Life.}

Wasirington, Pa., July 31, 1899.

To the Editor:-Apropos of the editorial on "Retention of Life," in the Jourval of July 29, allow me to mention two cases which came under my observation in the past two years, while an interne in Western Pennsylvania Hospital.

The first patient, a slender youth of 19 years, slipped while attempting to boara a moving train. The wheels crushed the right upper arm, right side of the pelvis, and left thigh. IIe reached the hospital in ten or fifteen minutes. Bleeding had stopped, bui the cinder-covered bowels were protruding over the crushed right os innominatum and lateral abdominal wall. The patient was conscious and rational for fully an hour after the injury, until he died.

In Oetober, 1897, a young tramp was found beside the Pennsylvania tracks, and brought to the hospital by ambulance. Examination showed both thighs entirely severed from the body, so closely to the pelvis that no operation could have given the needed flaps. The wounds were merely dressed; yet the patient lingered for almost a week. During this time death was expected almost hourly, yet consciousness remained till near the end.

To my mind such cases illustrate Nature's method of arresting hemorrhage from scvered vessels-torsion. In this section of the country some surgeons rely almost exclusively on twisting the arteries to stop bleeding during an operation, and I have seen no untoward results, even when the popliteal and brachial arteries were twisted. The method certainly is deserving of more prominence than our works on surgery give it. Very truly yours, Tilos. Wray Grayson, M.D.

[Arresting hemorrhage by torsion has been discussed in medical journals, is mentioned in most of the text-books, and is used to a great extent by many surgeons. Our correspondent is mistaken if he thinks the method is not recognized.--ED.]

\section{Yellow Fever.}

Washington, D. C., Aug. 5, 1899.

To the Editor.-Among the outbreaks of yellow fever that have prevaileci at Fortress Monroe, Va., and its vicinity let me mention one that has never been reported. In the early part of August, 186!, I had just come from quarantine duty at the mouth of the Rio Grande River, Texas, and being ordered to Fortress Monroe, found a French man-of-war quarantined in Hamptron Roads because of yellow fever. Many of the crew having died, as well as the medical officers, the ship was visited daily by a surgeon from the fort, who went unrestrained about his duties after crming ashore. It was not long, however, before an unmistakable case of the fever broke out in a member of the family of one of the surgeons who had most to do with the fever patients on shipboard. We decided to keep the matter strictly secret, even from the commanding officer, and await developments. Happily the patient made a good recovery, and the disease did not spread. To this day no one but the two medical cfficers in attendance have ever known of its existence. To be sure, one case does not demonstrate much, but this instance shows the transmissibility of the disease, and the fact that its spread was controlled by isolation, and perhaps secrecy; for had the presence of yellow fever become known at that time among the twelve hundred people in this fort, many of them women and children, there is no telling how the panic ensuing from publicity of the fact would have ended.

Irving C. Rosse. 